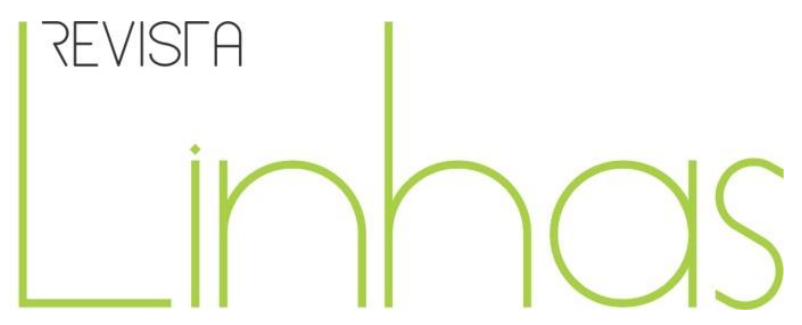

\title{
Relatórios de estágio supervisionado e a formação dos professores de música para a educação básica
}

\begin{abstract}
Resumo
Este texto apresenta análises iniciais sobre a proposição de estágio obrigatório, registrado em relatórios, aos alunos do Curso de Licenciatura em Música, da Faculdade de Artes, Letras e Comunicação da Universidade Federal de Mato Grosso do Sul, no período de 2014 a 2017. Estágio esse, realizado em escolas da rede pública e/ou privada de Campo Grande, nas três etapas que compõem a educação básica (Educação Infantil, Ensino Fundamental e Ensino Médio). O recorte temporal justifica-se por ser posterior à aprovação da Lei 11.769/2008, que altera a Lei de Diretrizes e Bases da Educação Brasileira, ao tornar a música conteúdo obrigatório na educação básica e, também, por tratar-se de período de vigência da reformulação do Projeto Pedagógico do referido curso. O objetivo das análises está orientado pela observação dos conteúdos das práticas propostas, como tradução da relação entre a objetivação do "professor de música" no espaço escolar e as "práticas de música", que oferta/constrói para esse espaço. Para tanto, analisamos 230 relatórios, aproximando-nos do campo de escolhas para realização, dados dos planos de aulas propostos e suas seleções de conteúdos. Em conclusão, identificamos equívocos sobre as práticas musicais oferecidas, uma vez que há naturalização das escolhas por conteúdos curriculares próprios das escolas específicas de música (dos conservatórios, por exemplo), e a música permanece como produto autônomo, indiscutível, sem relação com a prática social dos estudantes, abstrata e a-histórica.
\end{abstract}

Palavras-chave: Currículos. Conhecimentos e aprendizagem. Estágio Obrigatório.

\author{
Manoél Camara Rasslan \\ Universidade Federal do Mato \\ Grosso do Sul - UFMS - Campo \\ Grande/MS - Brasil \\ manoel.rasslan@ufms.br
}
Fabiany de Cássia Tavares Silva Universidade Federal do Mato Grosso do Sul - UFMS - Campo Grande/MS - Brasil fabiany.tavares@ufms.br




\title{
Practicum reports and the training of music teachers for basic education
}

\begin{abstract}
This text presents initial analyzes on the proposal of practicum activities, based in reports, to the students of the Music Teachers Trainning, at the Faculty of Arts, Letters and Communication of the Federal University of Mato Grosso do Sul, from 2014 to 2017. These practicum activities were carried out in public and/or private schools at Campo Grande (MS), in the three stages that compose the basic education (kindergarten, elementary and high school). The time cut is justified because it is after the approval of Law 11.769 / 2008, which made music a compulsory content in basic education, and also because it is the period of validity of the reformulation of the Pedagogical Project of this teachers training course. The objective of the analysis is guided by the observation of the contents of the proposed practices, as a translation of the relationship between the objectification of the "music teacher" in the school space and the "music practices" offered / constructed for this space. To do so, we analyzed 230 reports, approaching the field of choices for achievement, data from the proposed lesson plans and their content selections. In conclusion, we identify misconceptions about the musical practices offered, since there is a naturalization of the choices by specific music schools curricular contents (the conservatories, for example), and music remains as an autonomous product, indisputable, unrelated to the social practice, abstract and a-historical.
\end{abstract}

Keywords: Curricula. Knowledge Learning. Practicum Activities. 


\section{Notas introdutórias}

Este texto incursiona por percurso de investigação, ancorado em pauta do Programa de Pesquisa com Documentos Curriculares do/no Observatório de Cultura Escolar (OCE), que toma como fontes e objetos os documentos curriculares produzidos/prescritos para os espaços da educação formal e não formal. Espaços esses entendidos, de um lado, como instância de formação escolar, com objetivos educativos explícitos e ação intencional institucionalizada, estruturada e sistemática e, de outro, como uma possibilidade de produção, seleção e distribuição de conhecimento fora das estruturas curriculares do ensino tradicional, respectivamente.

Acresce-se a isso, que em virtude dos resultados já alcançados em pesquisas e/ou iniciações científicas, dissertações, teses, estamos nos aproximando do estudo de práticas curriculares na educação básica, construídas em estágios obrigatórios e/ou residências pedagógicas, sendo a última uma proposta em construção pelo MEC, a ser realizada nas etapas da Educação Infantil, Ensino Fundamental e Médio desenvolvida pelos cursos de Licenciatura.

Tal aproximação agrega evidências sobre a manutenção de diálogos, ou não, com os documentos curriculares prescritos para as redes de ensino e quais seriam eles; como são resolvidos os conflitos em torno das relações entre escola, sujeitos e conhecimentos e; como se materializam as ideologias da formação humana em diferentes contextos de proposições. Isso porque, tomamos a prática em sua capacidade de produzir embate e negociação em um espaço não só de "elaboração consensual”, mas de projetos em disputa por uma hegemonia, ainda, que provisória ou instável, numa luta incessante para a fixação de sentidos sobre currículo.

Nos limites deste texto, apresentamos as análises iniciais que resultam das primeiras aproximações com os relatórios de estágio obrigatório, realizados pelos alunos do Curso de Licenciatura em Música da Universidade Federal de Mato Grosso do Sul (UFMS). Esses documentos referem-se ao período compreendido entre os anos de 2014 a 2017, recorte temporal justificado pelos motivos que seguem: por ser um período posterior à aprovação da Lei 11.769/2008, que altera a Lei de Diretrizes e Bases da Educação Brasileira e torna a música conteúdo obrigatório, mas não exclusivo, na 
disciplina Arte presente na matriz curricular das escolas de Educação básica no Brasil; no período, implanta-se o Projeto Pedagógico do Curso (PPC) da referida licenciatura, o que acarreta orientações para o regulamento de estágio obrigatório.

Essa última delineando uma premissa particular, a forma pela qual um Projeto Pedagógico do Curso (PPC) estabelece “novas” verdades, isso porque:

Causa certa perplexidade a facilidade com que se põe em circulação linguagens e metáforas que nos levam a denominar de forma. A mesma sensação nos produz o entusiasmo com o qual, aparentemente, nos integramos a um novo universo de formas de falar sobre preocupações que pareçam ser novas porque, anteriormente, eram chamadas de outra maneira. As novas linguagens talvez sejam necessárias para abordar novas realidades, para descobrir algo verdadeiramente novo nelas; no entanto, frequentemente são a expressão da capacidade que os poderes e as burocracias têm para padronizar as maneiras de ver e de pensar a realidade em função de determinados interesses. São em outros casos, criações de especialistas em busca de fórmulas para expressar suas concepções e propostas com mais precisão, mas também com a finalidade de manter seus privilégios. Essa volatilidade da vigência das linguagens deveria ser um ótimo motivo de reflexão, por muitas razões. (SACRISTÁN, 2011, p. 7)

Os fatores norteadores escolhidos estão relacionados à formação dos professores de música para o espaço escolar, bem como as práticas propostas e a relação das mesmas com as práticas de música construídas e oferecidas pelos estagiários em sala de aula. Isso revela conceitos de música, a escolha de forma de transmissão desses conceitos oriundos da seleção de conhecimentos, da cultura, que encontram, ou não, problemas na sua distribuição.

A linguagem que escolhemos na educação nunca é neutra, porque com ela compreendemos a realidade educacional de uma forma e não de outra, adotamos um ponto de vista, destacamos determinados problemas, tomamos posição diante deles e expressamos nossos desejos. Ao mesmo tempo, estamos descuidando, esquecendo e até negando outras possibilidades. (SACRISTÁN, 2011, p. 7-8)

Diante disso, selecionamos apenas relatórios de estágios realizados no espaço da disciplina Arte, também, considerado de democratização do conhecimento musical, uma vez que se destina a todos os alunos matriculados. Espaço esse, diferenciado dos demais, 
tais como grupos vocais e instrumentais (coros, bandas, conjunto de flautas doce), cujos critérios de seleção podem excluir os que forem considerados inaptos para a prática musical proposta.

\section{O que registram os relatórios de Estágio Obrigatório da/na trajetória de formação}

Para a apresentação de seus relatórios são orientados por formulário composto de itens, que organizam as informações coletadas pelos estagiários na primeira fase da atividade, relativa à observação do campo de estágio, seguida da segunda fase, relativa à regência de aulas. As aulas a serem ministradas pelos estagiários seguem orientação do professor de estágio obrigatório no Curso de Licenciatura em Música, realizadas de acordo com o plano do professor da disciplina na escola, denominado professor supervisor do estágio.

Os quatro semestres de Estágio Obrigatório, desenvolvidos a partir do terceiro ano do Curso de Licenciatura, são parte do que no Projeto Pedagógico do Curso (PPC) relaciona-se aos Conteúdos de Dimensão Prática. Além do Estágio Obrigatório, ainda, encontramos no mesmo rol de conteúdos seis semestres de Prática de Ensino em Música, que objetivam a formação docente. E, por fim, apresenta Disciplinas de Práticas Musicais constituídas por quatro semestres de Canto Coral; quatro semestres de Instrumento Musicalizador; um semestre de Oficina de Produção e Montagem Musical; dois semestres de Regência Coral.

Entendemos, a partir do Projeto Pedagógico do Curso de Licenciatura em Música da UFMS, aprovado para implantação a partir do primeiro semestre de 2014, que os demais conteúdos constantes da Estrutura Curricular, teóricos ou práticos, deviam se refletir nos seis semestres de Prática de Ensino em Música e, portanto, no entendimento da educação musical em espaços diversos, incluindo aí o espaço escolar. Portanto, durante os seis semestres da disciplina Prática de Ensino em Música, o foco seria a construção e proposição de práticas musicais educativas para o contexto escolar.

Do montante de duzentos e trinta relatórios, correspondentes ao número de alunos matriculados nas disciplinas de Estágio Obrigatório I, II, III e IV, ofertadas do 
quinto ao oitavo semestre do curso, percebemos que 174 (76\% das matrículas) ocorreram em escolas de educação básica, públicas ou privadas; 56 (24\% das matrículas) em instituições que oferecem o ensino específico de música, isto é, conservatórios, escolas de música, associações, organizações não governamentais, bandas de música, coros, orquestras, etc. A figura que segue registra tal percepção:

Figura 1 - Estagiários matriculados entre 2014 e 2017

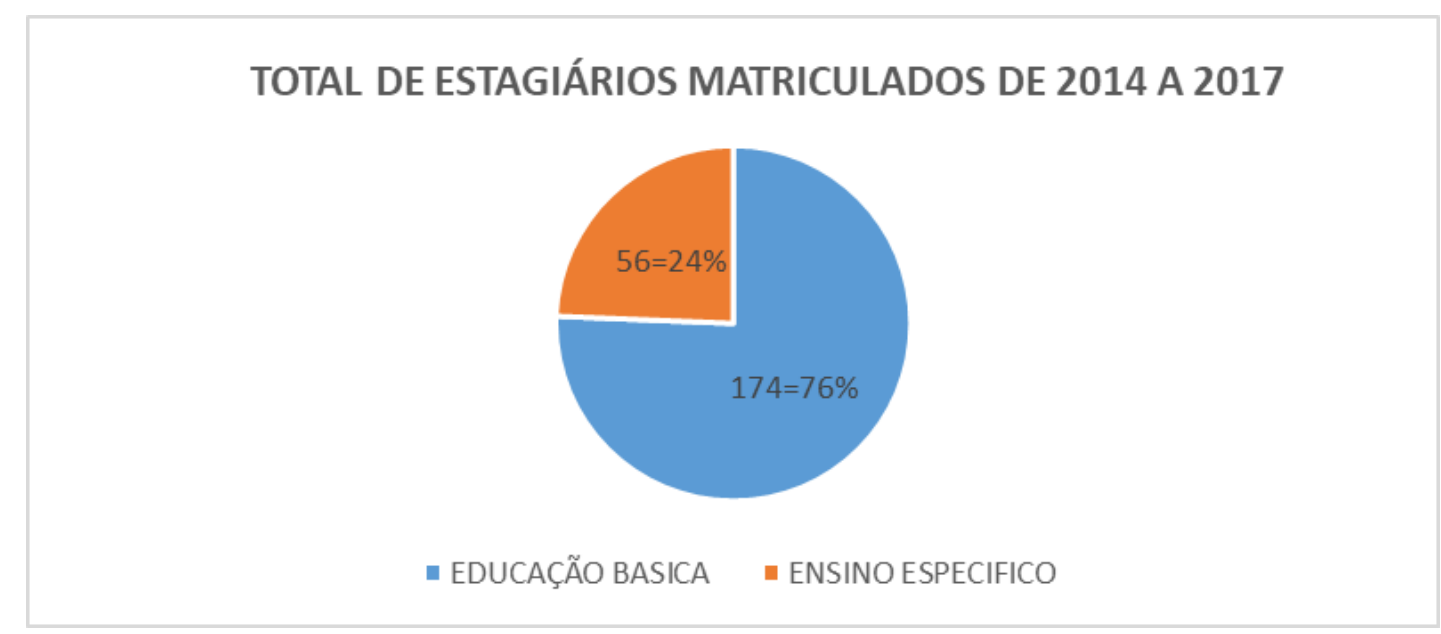

Fonte: Produção dos Autores.

O gráfico acima apresenta número expressivo de alunos em escola regular como espaço de estágio. Isso é reforçado pelo gráfico abaixo, que registra escolhas entre as escolas da educação básica e os espaços da educação específica de música, por semestre:

Figura 2 - Local de atuação dos estagiários

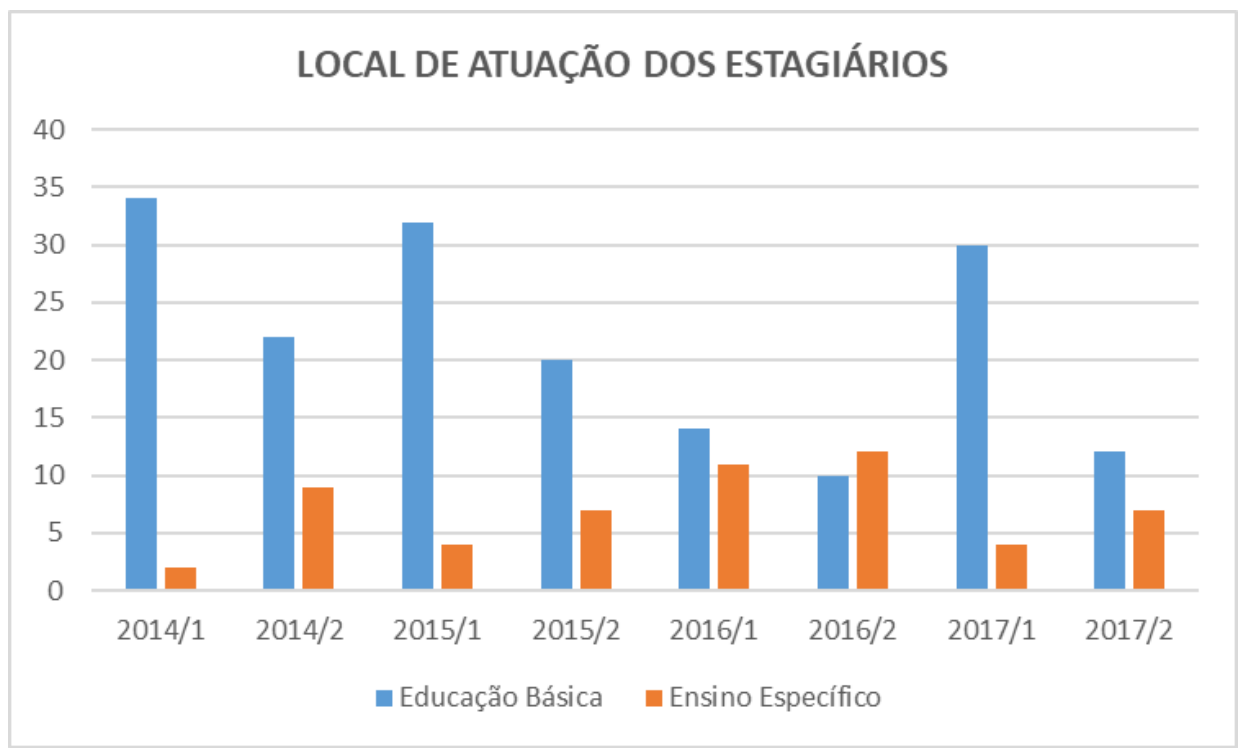

Fonte: Produção dos Autores. 
Os fatores considerados nas análises aqui propostas circunscrevem-se à escolha dos campos de estágio, de um lado, porque o regulamento de estágio orienta os alunos, preferencialmente, para as escolas; de outro, percebemos que há estagiários nas escolas de educação básica que, ao invés de atuarem na disciplina Arte, existente na matriz curricular, optam em realizar suas práticas de ensino em projetos que acontecem em contraturno, a exemplo de: oficinas de instrumentos musicais (violão, flauta-doce, etc.), bandas e coros.

Os projetos mencionados selecionam alunos interessados e, embora tenham aulas coletivas, obedecem aos padrões do ensino oferecido nas escolas específicas de música. Sendo assim, nessas primeiras aproximações, descartamos os relatórios oriundos de projetos dessa natureza, selecionando para as análises apenas os relatórios de alunos em disciplina prevista na matriz curricular da educação básica. Desta forma, o gráfico a seguir representa a situação mencionada.

Figura 3 - Atuação nas escolas de educação básica

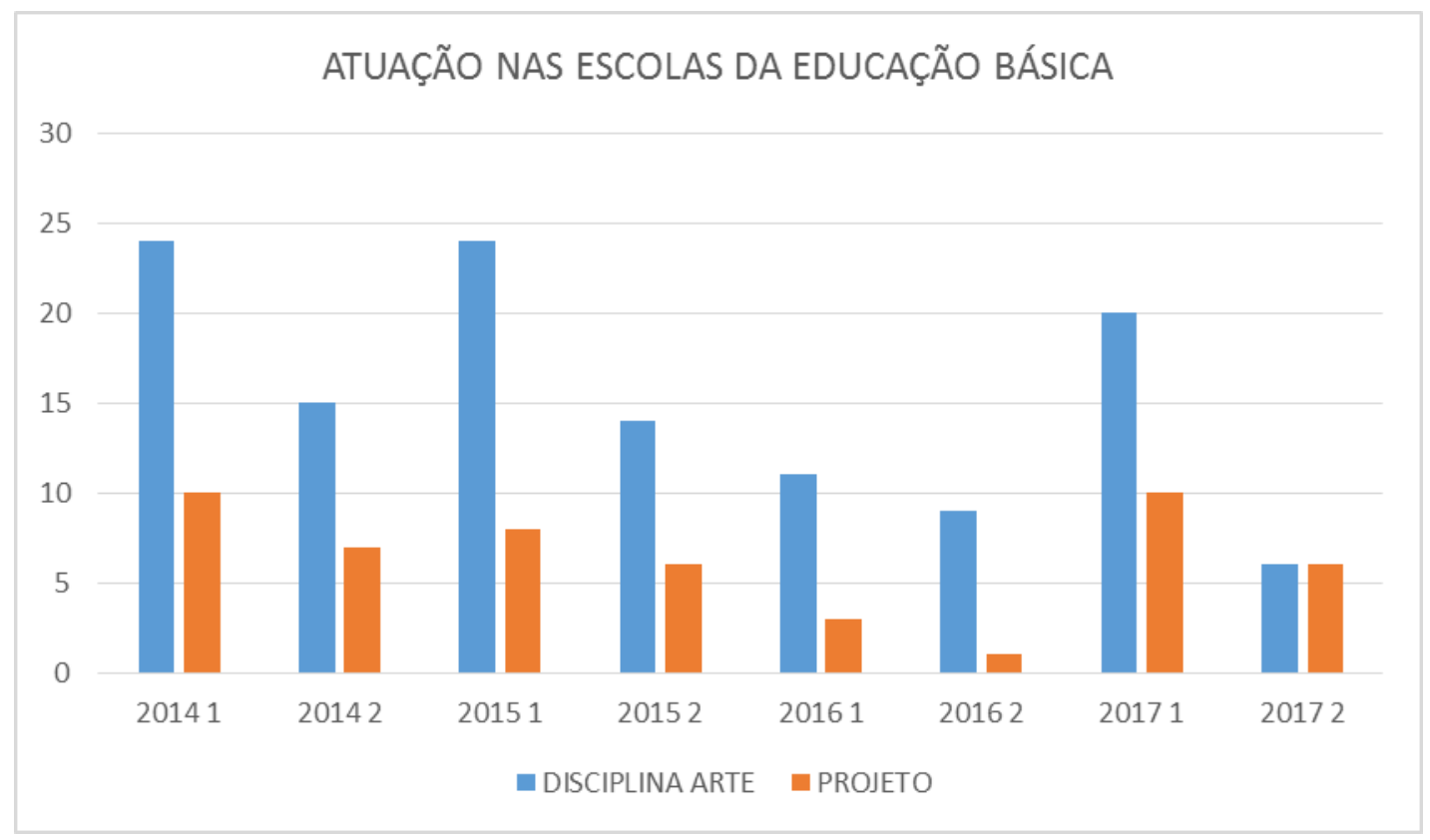

Fonte: Produção dos Autores.

Em relação à escolha do espaço para atuação, observamos que os licenciados em música, já formados e atuantes profissionalmente, preferem a escola específica de música por vários motivos, entre eles, Penna (2004) ressalta: 
Talvez uma das razões dessa preferência seja o fato de que, além de mais valorizadas socialmente, as escolas especializadas são instituições guiadas por uma concepção de música e de prática pedagógica que, por um lado, encontra ressonância na própria formação dos professores e, por outro, não é compatível com as difíceis condições de trabalho e as exigências desafiadoras das escolas públicas de ensino fundamental e médio. (PENNA, 2004, p. 7)

Em investigação com sujeitos licenciados egressos do Curso de Licenciatura em Música da Universidade Federal de Mato Grosso do Sul, único curso presencial público e gratuito do Estado, são desvelados, para além de fatores como a sobrecarga de atividades exigidas dos professores e a precarização do trabalho docente, que desestimulam a opção dos formandos por atuarem nas escolas de educação básica, o descompasso entre a formação recebida e as práticas docentes nessas escolas.

Dos sete professores entrevistados, cinco atuam na disciplina de Arte e todos declararam que a formação que tiveram não os preparou para estar onde estão. Tal depoimento nos faz refletir o quanto o Curso de Música está distanciado da escola, oferece uma formação engessada, que ilude o aluno, fazendo-o achar que seus conhecimentos musicais são suficientes para atuar em sala de aula, além de, cada vez mais, enfatizálos. (MELLO, 2017, p. 123)

O distanciamento dos alunos formados das escolas da educação básica como local de atuação profissional, assim como a falta de formação adequada, apontados por Mello (2017), indicam a necessidade de práticas musicais preparatórias para o professor de música para a escola básica. Práticas essas, que se diferenciam das práticas musicais observadas na educação específica em música e/ou nos projetos que envolvam conjuntos musicais fortemente vinculados à performance.

Esses grupos musicais, representados por bandas, coros, grupos de flautas, etc., embora presentes na educação básica em escolas públicas e/ou privadas, estão mais alinhados ao ensino oferecido pela escola específica de música, a exemplo do conservatório. Dessa forma, justifica-se a proposição da investigação dos relatórios de estágio, como forma de compreender como as práticas musicais formativas têm proporcionado aos estagiários a construção e oferta de práticas musicais para a disciplina Arte. 
A disciplina Arte, presente nessa condição, na Educação Básica brasileira desde a Lei de Diretrizes e Bases da Educação Nacional n 9394/96, passa a ser assumida por professores licenciados em Artes Visuais, Música, Teatro e Dança.

\section{Das práticas musicais na formação de professores de música às práticas musicais por eles construídas para a educação básica}

Dos itens constantes dos relatórios encontrados e selecionados para nossas primeiras aproximações, destacamos o plano de aula, por apontar para a seleção e forma como os conhecimentos musicais são abordados e/ou transmitidos, desvelando a relação entre as práticas formativas propostas no curso de licenciatura e a sua relação com as práticas musicais ofertadas pelos estagiários no espaço escolar.

Dessa forma, definimos o que consideramos como prática, na possibilidade da relação entre pessoa(s) e música(s), no que se refere aos aspectos de apropriação e transmissão, da forma tratada por Kraemer (2000), ao refletir sobre o campo da pedagogia da música. A dimensão pedagógico-musical envolve toda prática músicoeducacional que se dá em aulas em diversos espaços, escolares ou não, presente em toda cultura musical em processo de formação.

A prática musical seria simples proposição para apropriação e transmissão de conhecimento musical no processo de ensino-aprendizagem, não fosse pensarmos no habitus que lhe dá estrutura (BOURDIEU, 2009). Para este autor, os agentes trazem para o campo níveis de capitais (econômico, cultural, social e simbólico) que, intermediados por habitus, estruturam campo determinado em que esses agentes se envolvem e dão sentido aos seus interesses.

Sendo assim, essas práticas revelam mais do que uma ação ingênua e desinteressada, uma vez que representam a tentativa de seleção e legitimação do que se pretende validar, no espaço escolar, como conhecimento.

Ao analisarmos os relatórios selecionados, observamos a preocupação dos estagiários com a estrutura das escolas, principalmente no que diz respeito à falta de instrumentos musicais. Os relatos revelam uma situação não uniforme nas escolas, pois aquelas que possuem projetos em contraturno (bandas, fanfarras, coros, grupos 
instrumentais), possuem instrumental, outras não possuem qualquer instrumento musical.

Com relação às salas de aulas, os espaços físicos são os mesmos utilizados para outras disciplinas da estrutura curricular, sem isolamento acústico que permita a produção sonora e/ou escuta de obras musicais sem que as demais aulas sejam prejudicadas, o que dificulta atividades que exijam movimentação de alunos e produção de sons. Vale destacar, que os projetos constantes em contraturno, acontecem em espaços abertos como quadras de esportes, o que também prejudica o bom andamento das atividades previstas.

No tocante aos planos de aula, observamos a orientação influenciada pelos métodos ativos de educação musical, tomando como referência o livro organizado por Mateiro e Ilari (2011). Dos métodos referidos, são citados principalmente os de autoria da primeira geração de educadores musicais: Jacques Dalcroze, Edgar Willems, Zoltán Kodály, Carl Orff. Encontramos relatos de aulas com propostas de audição vinculadas ao pensamento de Murray Schafer (2011), que propõe a paisagem sonora como possibilidade para escuta ativa e preocupada com o homem e a transformação do meio ambiente.

Os métodos ativos de educação musical, estruturados pelos autores citados, constantemente são referenciados nos planos de aula com objetivo de exercitar a percepção de parâmetros musicais (duração, altura, intensidade e timbre) e a proposição de escuta de repertório trazido pelos estagiários e oriundos da música de concerto (música erudita) e da música folclórica. Não há relatos da preocupação com a música cotidiana dos alunos, aquelas que fazem parte da sua cultura.

É importante compreender, que os métodos ativos de educação musical, principalmente os surgidos na primeira metade do século $X X$, os mais referenciados, objetivam proporcionar uma vivência concreta do fenômeno musical antes da abstração e técnica que levasse à leitura, escrita e performance. A perspectiva de facilitar a iniciação musical e distanciá-la de uma atividade que valorizasse, sobretudo, a técnica instrumental em lugar da compreensão musical.

Contudo, eles estruturaram-se dentro da linguagem ocidental, considerando o repertório erudito e folclórico, em especial aquele construído em obediência aos códigos, 
normas e estrutura da música europeia e, em última análise, tendo foco a performance viva e livre desta música.

Como exemplos dos objetivos das aulas propostas, encontramos:

Para a educação infantil:

Apreciar e conhecer os principais instrumentos da orquestra;

Desenvolver percepção auditiva, a curiosidade pelos sons, articulação dos lábios e concentração. (Relatório A, de 2014/1)

Explorar e manusear diferentes materiais, desenvolver a criatividade do aluno, trabalhar datas comemorativas e seus significados e ajudar no desenvolvimento da leitura e escrita. (Relatório A, de 2015/2)

Exemplos de objetivos para aulas da Educação Fundamental, apontam para:

Conhecer um repertório de músicas folclóricas e brincadeiras de roda; memorizar as notas musicais e a escala de dó maior, ascendente e descendente; vivenciar o ritmo das músicas propostas, por meio do movimento. (Relatório B, de 2014/1)

Parâmetros musicais - intensidade, altura, duração e timbre; canções infantis. (Relatório A, de 2014/2)

Proporcionar aos alunos condições básicas para que toquem músicas populares no violão através de leitura de cifras,

desenvolvam habilidades motoras e rítmicas através da percussão corporal, e trabalhem músicas em grupo. [Sic]. (Relatório A, de 2015/1)

Canto, técnica de execução, literatura, apreciação. (Relatório B. de 2015/2)

Compreensão de fórmula de compasso, compreender o tempo forte, assimilar a contagem dos compassos em determinados ritmos. (Relatório B, de 2017/1)

Timbre e intensidade na música renascentista.

Audição de obras renascentistas. Instrumentos musicais da renascença. Parâmetros musicais (duração, intensidade, altura, timbre).

Melodia, harmonia, notação musical. (Relatório A, de 2017/1) 
Para o Ensino Médio, os objetivos propostos são reforçados em:

Compreender os períodos onde a música se situa em determinado ano ou século, reconhecer os instrumentos em geral dos períodos, os compositores, as obras mais importantes para o período;

Reconhecimento de algumas peças e compositores do período abordado, através de mídias apresentadas;

Abordagem sobre os instrumentos da época, identificar a origem, a importância, onde se era utilizado, como era a fabricação e distinguir o som de cada um dos que forem abordados;

Relacionar peças de compositores nos dias atuais e identificar se há algum vestígio do que se era executado e o que se escuta hoje na mídia; Criar uma música de acordo com o período abordado. (Relatório B, de 2014/2)

Promover a percepção extramusical (paisagem sonora) e a interação com a mesma. (Relatório A, de 2017/1)

Os exemplos acima permitem localizar a necessidade de transmitir elementos musicais sem articular os mesmos com a música ouvida e/ou praticada pelos alunos dentro e fora do contexto escolar. O que para o estagiário é conhecimento, parece não ser razoável para um grupo de alunos que não teve condição de compreender anteriormente os códigos propostos a serem exercitados e compreendidos sem reflexão aprofundada sobre a linguagem musical aos quais se refere.

A seleção de conhecimentos da cultura tem sido balizada pelo que é hegemônico, representado pelos agentes com maiores capitais e, consequentemente dominantes, melhores posicionados no campo (BOURDIEU, 2009). Ao se pensar música como produto e processo das sociedades, não é difícil constatar que o que é naturalizado como conhecimento a ser legitimado pela escola é o que tem maior poder de representação e distinção.

No entanto, ao se propor outras músicas, para além daquela oriunda e orientada pela alta cultura, o desconforto sobre o que deve ser transmitido se instala. Moreira (2010), ao refletir sobre currículo e controle social aponta para a necessidade de se ouvir quem tem sido constantemente calado e excluído de decisões, e afirma:

[...] de pretender ensinar à criança na escola a atividade que ela já realiza fora do horário escolar, como alguns críticos apressados parecem julgar ser a intenção de todos os que se apõem à ênfase exagerada no saber 
sistematizado. Não desejo romantizar a cultura popular, nem fazer dela o único conteúdo do currículo. A escola precisa criticá-la, para que seus aspectos restritivos e repressivos sejam superados, assim como precisa identificar e eliminar os componentes ideológicos que têm tomado o saber dominante um instrumento de manutenção de privilégios. (MOREIRA, 2010, p. 89)

As inquietações em relação ao que está proposto como prática musical para a escola e descrito nos relatórios analisados, levam a indagações permanentes, isto é: se é necessário compreender os parâmetros sonoros, qual o sentido de compreendê-los? Como esses parâmetros são ouvidos no repertório musical proposto? Se é necessário aprender os nomes das notas musicais, com qual finalidade? Que sentido esses conhecimentos selecionados têm para os alunos e o repertório que eles ouvem cotidianamente?

Ao refletir sobre os conteúdos musicais propostos para Educação Básica, ressaltamos indícios do vínculo dos mesmos apenas com a música ocidental erudita ou folclórica. Pereira (2014) aponta para a necessidade de se pensar a prática musical mais próxima da prática social, o que não parece ser preocupação dos estagiários. A música proposta por eles, portanto, ganha caráter de autonomia e a-historicidade, apontando para a necessidade de formação do "bom gosto" musical.

Autores da educação musical, tais como Penna (2018) e Kraemer (2000), têm apontado para a necessidade de se entender a música não como linguagem universal, mas, sobretudo, como linguagem construída socialmente e que, portanto, deve ser refletida no plural, Música(s). A própria educação musical configura-se como subcampo do conhecimento que mantém diálogo com outros campos como a Sociologia, Psicologia, Filosofia, História, etc., mas sem perder seu principal foco, o de apropriação e distribuição de conhecimentos musicais.

No elenco das disciplinas encontradas no Projeto Pedagógico do Curso, encontramos como ementa para as Práticas de Ensino em Música, o reforço da necessidade de se conhecer as metodologias ativas de educação musical, práticas musicais desenvolvidas em projetos de orquestras, bandas e coros. Embora sejam importantes, esses métodos e práticas não se aplicam na sala de aula no contexto 
escolar, estando mais próximos da seleção de música delimitada no tempo, espaço e cultura determinada e à execução instrumental da mesma.

Aqui, talvez, esteja localizada a construção de práticas equivocadas e ofertadas pelos estagiários para o contexto escolar da educação básica. Pereira (2014) aponta para o problema do vínculo das licenciaturas em música com o que ele conceituou como habitus conservatorial, a partir da obra do sociólogo Pierre Bourdieu.

\begin{abstract}
Habitus conservatorial seria próprio do campo artístico musical e estaria transposto (convertido) ao campo educativo na interrelação estabelecida entre esses dois campos. E seria incorporado nos agentes ao longo do tempo no contato com a instituição, com suas práticas, com seu currículo enquanto objetivação de uma ideologia. Assim, as instituições de ensino musical - como resultado da história iniciada pelos conservatórios poderiam ser entendidas como opus operatum: campo de disputas que tem no habitus conservatorial o seu modus operandi. (PEREIRA, 2014, p. 94)
\end{abstract}

A partir do conceito desenvolvido por Pereira (2014), observa-se a orientação curricular para os cursos de licenciatura em música obedecendo aos padrões do conservatório, portanto, naturalizando a seleção de conhecimentos e maneiras de ensinar próprios de uma instituição que tem por finalidade a preparação de músicos, de pessoas "talentosas" para o campo artístico. Campo esse, que encontrará problemas quando se trata de ensinar para todos, como é o caso do contexto escolar.

\title{
Notas finais
}

As análises iniciais dos relatórios permitem um panorama sobre as escolhas desses alunos por campos de atuação, que indicam a escola como preferência. Contudo, quando refletimos sobre os espaços da escola de educação básica onde os mesmos atuam, a disciplina Arte não aparece como prioridade na escolha.

Dessa forma, os projetos que acontecem em contraturno, a exemplo das bandas, coros, grupos instrumentais de flauta, violão, sustentam alto número de escolhas em contraposição à disciplina Arte, frequentada por todos os alunos matriculados, que implica práticas musicais diferenciadas dos projetos, cuja orientação tem base no modelo do ensino do conservatório, próprio do campo artístico. 
Percebemos, ainda, que se encaminham para a disciplina Arte equívocos sobre as práticas musicais oferecidas, uma vez que há naturalização das escolhas por conteúdos curriculares próprios das escolas específicas de música (dos conservatórios, por exemplo), e a música permanece como produto autônomo, indiscutível, sem relação com a prática social dos estudantes, abstrata e a-histórica.

Ainda que iniciais, em resumo, as análises apontam para a necessidade de se desnaturalizar as escolhas operadas no currículo escolar, em relação à música e ao seu ensino, abrindo possibilidades de se considerar a cultura dos alunos no contexto da escola e permitindo que se construam conhecimentos musicais mais significativos e críticos para todos. Entendemos como conhecimentos musicais mais significativos e críticos, aqueles operados na/pela mediação entre as objetivações das esferas cotidianas e não cotidianas da vida social humana e, dessa forma, mediadoras das relações entre as motivações particulares de cada indivíduo e as objetivações do gênero humano.

\section{Referências}

BOURDIEU, Pierre. O senso prático. Trad: Maria Ferreira. Petrópolis RJ; Vozes, 2009.

KRAEMER, Rudolf-Dieter. Dimensões e funções do conhecimento pedagógicomusical. Em Pauta, Porto Alegre, Ano 1, nº 16/17, p. 50-73, 2000.

MATEIRO, Teresa; ILARI, Beatriz. Pedagogias em educação musical. Curitiba: InterSaberes, 2011.

MELLO, Jaqueline Cavalcanti Borges. O trabalho e o bem-estar do professor de música nas escolas de educação básica de Campo Grande, MS. 2017. (Dissertação de Mestrado) - Programa de Pós-Graduação em Educação da Universidade Católica Dom Bosco. Campo Grande, MS, 2017. 
MOREIRA, Antônio Flávio Barbosa. Currículo e Controle Social. In: PARAÍSO, Marlucy Alves (Org.) Antônio Flávio Barbosa Moreira: pesquisador em currículo. Belo Horizonte: Autêntica Editora, p. 79-116, 2010.

PENNA, Maura. A dupla dimensão da política educacional e a música na escola: II - da legislação à prática escolar. Revista da ABEM, v.11, p. 07/16, 2004.

PENNA, Maura. Música(s) e seu ensino. Porto Alegre: Sulina, 2018.

PEREIRA, Marcus Vinícius Medeiros. 0 ensino superior e as licenciaturas em música: um retrato do habitus conservatorial nos documentos curriculares. Campo Grande, MS: Ed. UFMS, 2013.

PEREIRA, Marcus Vinícius Medeiros. Licenciatura em música e habitus conservatorial: analisando o currículo. Revista da ABEM, Londrina, v.32, n. 22, 90-103, jan./jun., 2014.

SACRISTÁN, José Gimeno. et al. Educar por competências: o que há de novo? Tradução de Carlos Henrique Lucas Lima. Revisão técnica: Selma Garrido Pimenta. Porto Alegre: Artmed, 2011. 264p.

SCHAFER, Raymond Murray. O ouvido pensante. Tradução de Marisa Trench de O. Fonterrada, Magda R. Gomes da Silva, Maria Lúcia Pascoal. São Paulo: Editora da Unesp, 2011, 408 p.

UFMS. Projeto Pedagógico do Curso de Música. Campo Grande, MS, 2014.

Recebido em: 06/09/2018

Aprovado em: 27/11/2018

Universidade do Estado de Santa Catarina - UDESC Programa de Pós-Graduação em Educação - PPGE Revista Linhas

Volume 20 - Número 42 - Ano 2019 revistalinhas@gmail.com 